\title{
Kinetic studies for the biosorption of chromium using cherry leaves (Muntingia calabura L.)
}

\author{
R. Aathithya, J. Rajani Sowparnika, V. Balakrishnan* \\ Department of Biotechnology, K. S. Rangasamy College of Technology, \\ Tiruchengode - 637 215, Tamil Nadu, India \\ *E-mail address: palanivbalu@gmail.com
}

\begin{abstract}
Biosorption is an attractive technology which is used for the sorption of substances by a biomaterial. In this present work the heavy metal chromium was subjected to biosorption because of their non-degradability nature and causes water and land pollution. Cherry leaves were used as a biomaterial for the biosorption. Kinetic studies were performed for the biosorption experiment. From the experiment it was found that the reaction follows pseudo first order reaction because of the larger value of regression coefficient R2 and lower value of standard errors $\left(\chi^{2}\right)$ for pseudo first order reaction than second order reaction.
\end{abstract}

Keywords: Chromium; Biosorption; Kinetic studies; first order and second order reactions

\section{INTRODUCTION}

The emission of toxic fumes into the air causes an acid rain. When the acid rain falls, it contaminates local natural waterways including streams, rivers and lakes. This causes the death of many aquatic animals.Contamination of heavy metals which comes under inorganic division of contaminants in the environment is a major concern because of their toxicity and threat to human life and environment ${ }^{1,2}$. It is a hard metal of steely gray color and also it has a high melting point of $1907{ }^{\circ} \mathrm{C}$. It is odorless and tasteless metal. Many of it compounds are intensely colored. Chromium is important metal due to its high corrosion resistance and hardness.Chromium toxicity has serious effects in vivo due to carcinogenic, mutagenic and teratogenic potential and also it results in tissue damage. Chromium exists in several oxidation states (I-VI), more stable as $\mathrm{Cr}(\mathrm{III})$ and $\mathrm{Cr}(\mathrm{VI})^{3}$. Bioremediation is the process of breaking down or transforming hazardous materials into simple nontoxic substances by biological treatments. It is a collective term used to describe the use of biological systems such as microorganisms to decontaminate polluted soil, water and air $^{4}$.

Biosorption is an emerging and attractive technology which involves sorption of dissolved substances by a biomaterial. It is a potential technique for the removal of heavy metals from solutions and recovery of precious metals. The advantages of this method are the reusability of biomaterial, low operating cost, improved selectivity for specific metals of interest, removal of heavy metals from effluent irrespective of toxicity, short operation time, and no production of secondary compounds which might be toxic ${ }^{5}$. 


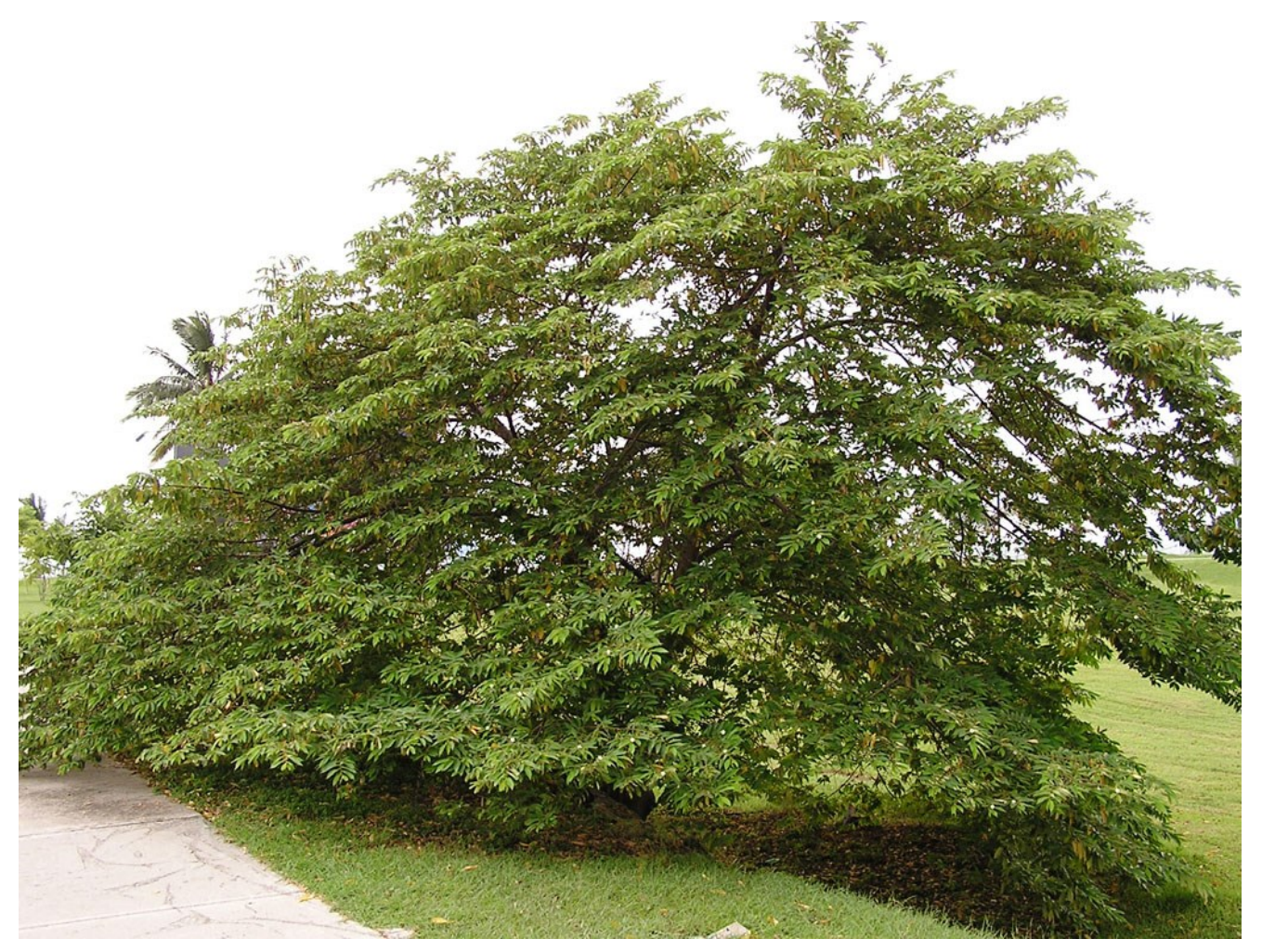

Photo 1. Muntingia calabura - tree.

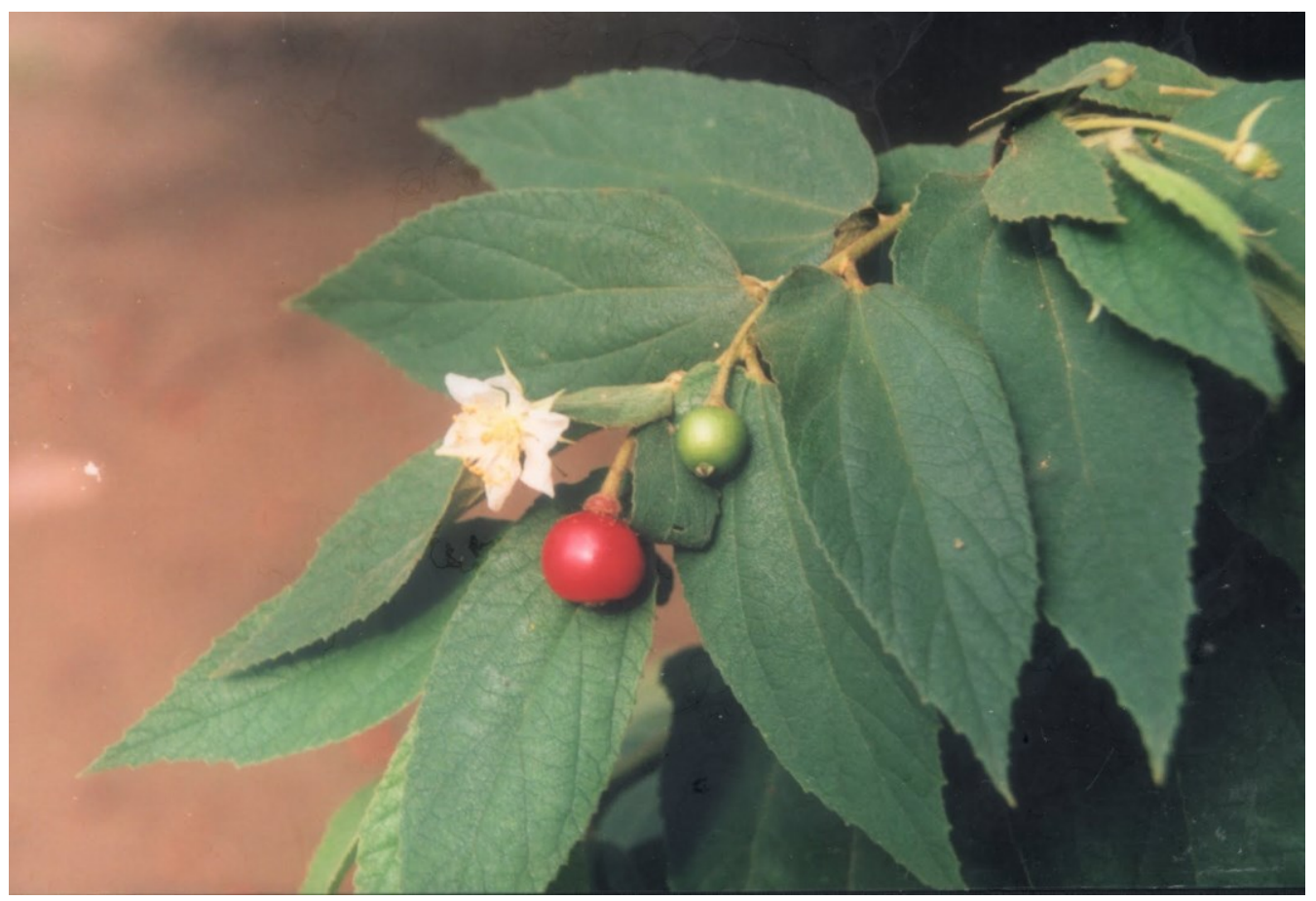

Photo 2. Muntingia calabura - flower and fruit. 
Pollution of water by industrial effluents of process industries is a serious problem in most countries. Industrial waste consists of both organic and inorganic substances ${ }^{6}$. In this present work kinetic studies were performed for the biosorption of chromium using cherry leaves.

\section{MATERIALS AND METHODS}

\section{1. Selection of the plant}

Cherry leaf was selected as adsorbent for removal of chromium ion in this study. The leaves were obtained from a Cherry tree located in K. S Rangasamy College of Technology (Autonomous), Tiruchengode. The plant was identified and authenticated by Botanical Survey of India Southern Circle, Tamil Nadu Agricultural University, Coimbatore. The binomial name of cherry leaves is Muntingia calabura $\mathrm{L}$.

\section{2. Preparation of leaf adsorbent}

Mature Cherry leaves were collected and it was washed thoroughly under running tap water to remove dust and any adhering particles. The leaves were then dried under sunlight for a few days until it became crisp. The dried leaves were crushed and blended to powder form using a blender. It was stored in an airtight plastic for further use to avoid contact with moisture in atmosphere.

\section{3. Preparation of chromium stock solution}

Stock solution of chromium of $1000 \mathrm{mg} / \mathrm{L}$ was prepared by dissolving $2.828 \mathrm{~g}$ of potassium dichromate in $1 \mathrm{~L}$ of distilled water. The working solution was prepared by diluting the stock solution.

\section{4. Chromium analysis}

Chromium content was analyzed using spectrophotometric method, as described in the Standard metthod ${ }^{7}$, to measure the concentrations of the $\mathrm{Cr}$. The reaction takes place between $\mathrm{Cr}$ and 1,5-diphenycarbazide results in the pink coloured complex. Then it was able to be spectrophotometrically analyzed at $540 \mathrm{~nm}$.

\section{5. Kinetics of adsorption}

Kinetics was studied by using pseudo first order and second order kinetics model. At different dosage of bioadsorbent such as $0.5,0.75,1.0,1.25 \mathrm{~g}$ the amount of chromium bioadsorbed was determined at an optimum concentration of chromium at $50 \mathrm{ppm}$.

Pseudo first order model of Lagergren equation is,

$$
\log \left(q_{e}-q_{t}\right)=\log \left(q_{e}\right)-\left(k_{1} / 2.303\right) \cdot t
$$

Pseudo second order model of Lagergren equation is

$$
t / q_{t}=1 / k_{2} q_{e}{ }^{2}+\left(1 / q_{e}\right) \cdot t
$$

where,

$$
\mathrm{q}_{\mathrm{e}}=\text { amount of chromium bioadsorbed at equilibrium (mg/l) }
$$


$\mathrm{q}_{\mathrm{t}}=$ amount of chromium bioadsorbed at time $(\mathrm{mg} / \mathrm{l})$

$\mathrm{k}_{1}=$ pseudo first order rate constant $\left(\mathrm{min}^{-1}\right)$.

$\mathrm{K}_{2}=$ pseudo second order rate constant $\left(\mathrm{g} \mathrm{mg}^{-1} \mathrm{~min}^{-1}\right)$.

Pearson's chi-squared test was used to analyze the goodness of fit for pseudo first and second order reactions model. Its properties were first investigated by Karl Pearson in 1900.

\section{RESULTS AND DISCUSSION}

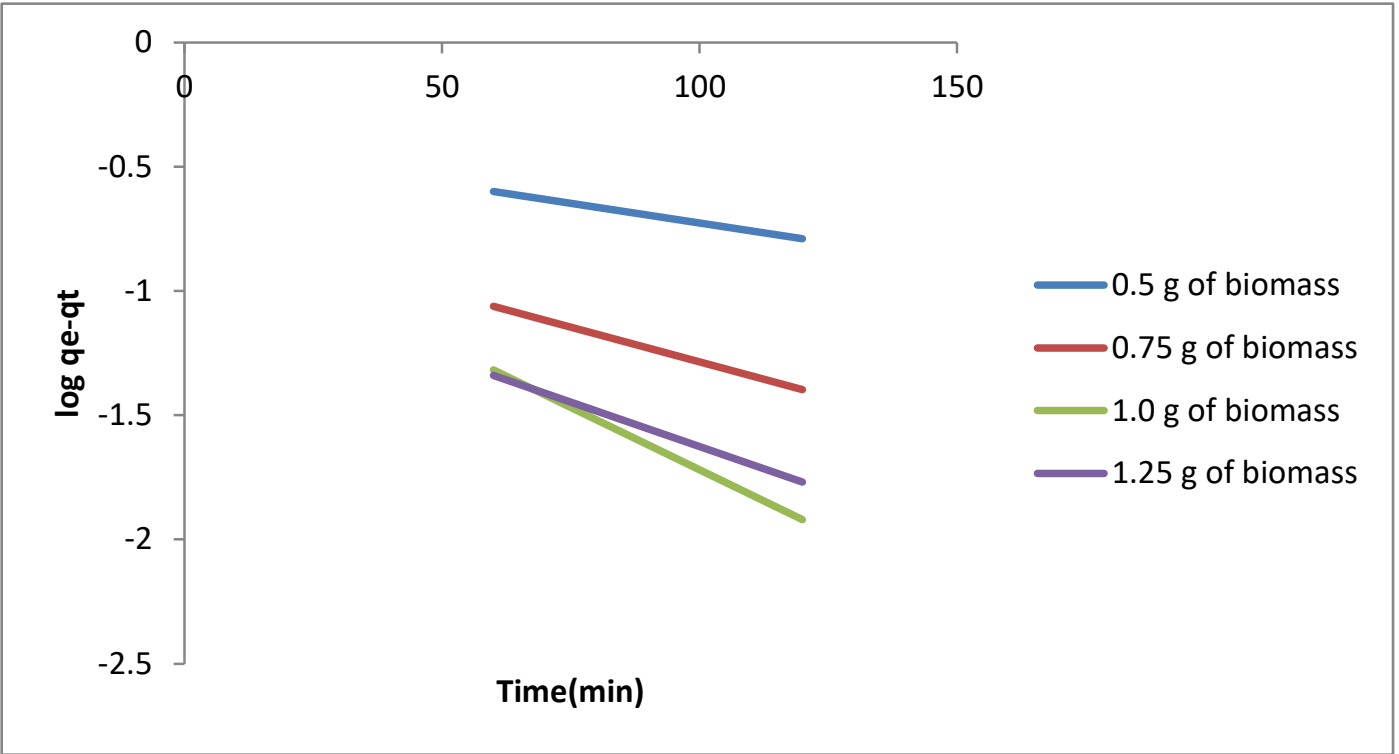

Fig. 1. Plots of Pseudo first order reaction of cherry leaf powder and chromium at $293 \mathrm{~K}$.

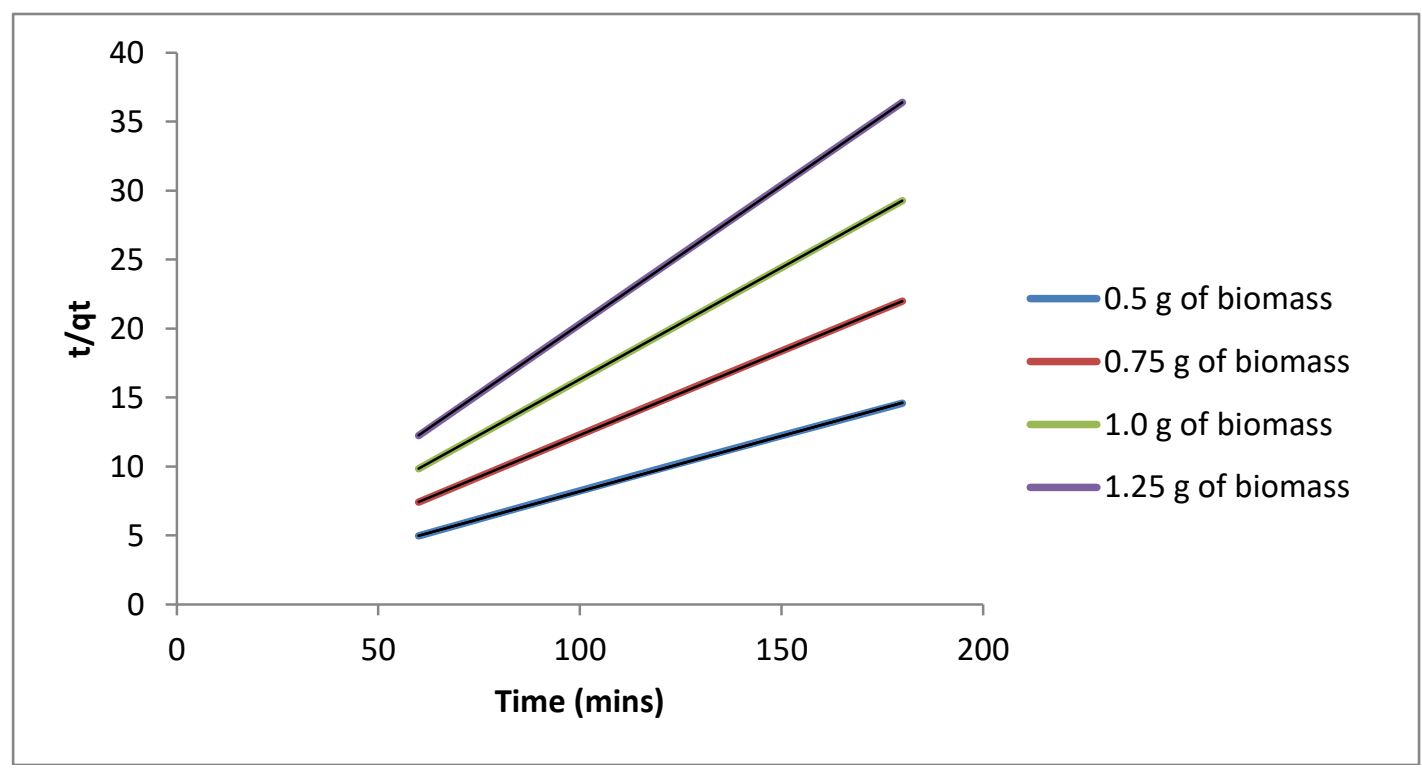

Fig. 2. Plots of Pseudo second order reaction of cherry leaf powder and chromium at $293 \mathrm{~K}$. 
Table 1. Parameters of pseudo first and second order reactions.

\begin{tabular}{|c|c|c|c|c|}
\hline & $\mathbf{K}\left(\mathbf{m i n}^{-\mathbf{1}}\right)$ & $\mathbf{R}^{\mathbf{2}}$ & S.D & $\boldsymbol{\chi}^{\mathbf{2}}$ \\
\hline $\begin{array}{c}\text { Pseudo First } \\
\text { order }\end{array}$ & $\mathrm{k}_{1}=6 \cdot 10^{-2}$ & 0.99 & 0.44 & 0.18 \\
\hline $\begin{array}{c}\text { Pseudo Second } \\
\text { order }\end{array}$ & $\mathrm{k}_{2}=0.140$ & 0.97 & 9.46 & 1 \\
\hline
\end{tabular}

From the Fig. 1 and 2 Table 1 shows that it was deduced that both pseudo first and second order reaction gives a straight line. In order to find the fitting of data, regression coefficient, Standard deviation and chi square analysis was determined. From the Table 1 it was found that the high regression coefficient and low standard error $\left(\chi^{2}\right)$ for pseudo first order reaction. So that experimental data fits with the pseudo first order reaction than the second order reaction.

\section{CONCLUSION}

From the kinetic studies it was observed that the reaction follows pseudo first order reaction. The experimental data fits well with the pseudo first order reaction than the second order reaction. This was confirmed from the larger value of regression coefficient R2 and lower value of standard errors $\left(\chi^{2}\right)$ of pseudo first order reaction than second order reaction.

\section{Acknowledgement}

The authors are gratefully acknowledge the Management, Principal, Professor \& Head, Department of biotechnology, K. S. Rangasamy College of Technology, for providing laboratory facilities to carry out the work successfully.

\section{References}

[1] Rajendran P., Gunasekaran P., Microbial Bioremediation, M.J.P. Publishers, Chennai (2007) 181-190.

[2] Boopathy R., Factors limiting bioremediation technologies, Bioresource Technology 74 (2000) 63-67.

[3] John G., Balachandran U., P. Rengarajulu., Journal of Applied Microbiology (2006) 52 (2006) 179-186.

[4] Sivasubramanian V., Phycoremediation - Issues and challenges, Indian Hydrobiology 9(1) (2006) 13-22. 
[5] Deepa Prabhu M., Thiruvenkatachari V., Journal of Physicochem. Eng. Aspects 301 (2006) 214-223.

[6] Balaji V., Datta S., Bhattacharjee C., Evaluation on Biological Treatment for Industrial Wastewater 85 (2005) 72-81.

[7] Standard Methods for the Examination of Water and Wastewater, American Public Health Association, Washington, DC, USA.(1998) 20th edition. 